An idea has, however, grown out of this long-continued agitation which promises practical results, and this is, for all civilized nations to agree on a uniform strength of what are known as "potent remedies," or as the French term it, "medicaments heroiques," and the International Congress, held in September, 1902, at Brussels, recommended such uniformity. The principal reason for establishing this kind of an international pharmacopeia is to secure uniformity in the dosage of such important medicines as solutions of arsenic and preparations of opium, digitalis, nux vomica, belladonna, etc., so that a patient traveling in any country and having a prescription containing a potent remedy runs little risk of danger on account of the substitution of Fowler's solution made by either a Swiss, German or English pharmacist for the one originally prescribed. For instance, if arsenical preparations were made throughout the world of 1 per cent. strength, all danger from this source would be removed.

It can not be hoped that the new United States Pharmacopeia will please everybody. No pharmacopeia in the world was ever published which was universally accepted by all of the affected interests. Anyone can be convinced of this fact who chooses to consult medical and pharmaceutic literature bearing on the pharmacopeias of the various countries. This is particularly the case with regard to admissions and expurgations. One pliysician or pharmacist sees in the book some drug or preparations which he has never used and possibly never heard of. Another looks through its pages and does not find his favorite remedy; but it must be remembered that the title of the book is "The Pharmacopeia of the United States of America," and a drug which may not be used in one section is largely used in some other. And again, some preparation which may have considerable local use finds no favor outside of a circumscribed locality, and it would be impossible to think of loading the Pharmacopeia with preparations which have merely a circumscribed use.

Neither can a pharmacopeia be expected to contain all of the new remedies which are exploited by the various manufacturing firms throughout the world. This everchanging, yet never-to-be-suppressed condition imposes on the revision committee a most difficult task of selection. It can only recognize the newer remedies which have stood the test of sufficient time io demonstrate their value, and of late years the "embarras de richesses" has been so pronounced, and one good new remedy has been so rapidly supplanted by something better (if the advertisements of the manufacturers are credited), that the task of the committee has been greatly increased. Nevertheless, it is believed that the new Pharmacopeia, when it appears, will be abreast of the times and be recognized as fully worthy to stand with any of its predecessors, and contain between its covers a list of medicinal substances with descriptions, tests and formulas for preparing the same, which will be recognized throughout the length and breadth of the land as authoritative.

Music for Insane.-The "Medical Times" says that the authorities of Manhattan Asylum, Ward's Island, are making systematic experiments with the music cure, and have treated a dozen cases of melancholia, giving them concerts an hour long every afternoon with the harp, violin and piano. They report, after a month's trial, that improvement is shown, and that patients suffering from acute mania and hallucinations show more mental alertness and cheerfulness, and that one patient has been assisted almost to recovery by the violin alone.

\section{CASE OF FUNNEL PELVIS WITH CESAREAN SECTION.}

CHARLES B. REED, M.D.

Assistant Professor of Obstetrics, Northwestern University Medical School; Associate Obstetrician Chicago Lying-in Hospital; Obstetrician Cook County Hospital. CHICAgo.

HISTORY.

On May 4, 1900, in my service at the Chicago Lying-in Hospital, I saw the patient, aged 19 , in her first confinement. She had been in labor twenty-four hours, the membranes had rupturerl and dilatation was complete. The unengaged head presented, mobile above the inlet in L. O. A., and the woman was ncarly exhausted by her long labor. The external meas. urements of the pelvis were small and the conjugata diagonalis could not be obtained. The outlet seemed contracted, but an estimation of the size of the child's head did not apparently preclude its passage and, with the usual preparations and precautions, a combined external and internal version was done. The anterior foot was seized and brought down and the extraction followed directly. No trouble was experienced until the head reached the inlet and refused to enter; under the com. bined use of pressure from above (on abdomen), the Walcher position and the Smellie-Veit method of delivery, the head slipped through the inlet, passed rapidly and without difficulty through the excavation to the bony outlet, where its progress was stopped. In spite of our utmost efforts the attempts to complete the delivery failed. The child was asphyxiated, craniotomy was done through the roof of the mouth and the mutilated head passed the contracted outlet with some difficulty.

In October, 1901, she reappeared, pregnant for the second time, but with no knowlerlge of the date of conception. She did not remember when her periods were interrupted, nor when she first felt life.

From examination it seemed probable that labor would occur about Feb. 1, 1902, and, appreciating the difficulties which the case presented, her own and her husband's consent was secured for the performance of any operation which would most nearly promise a living child.

Labor began at 2 a. m., February 16, and 8 a. m. she went to Wesley Hospital and was immediately prepared for cesarean section. No internal examination was made. The operation began three hours later, with the courteous assistance of Dr. Watkins and the resident hospital staff. Through the usual median celiotomy incision the uterus was delivered, the blood supply manually compressed and a median longitudinal incision made in the uterus, through which the child was easily extracted by the anterior foot. Contraction of the uterus was secured by massage and hot applications and the placenta was delivered. The opening in the uterus was closed by through-and-through sutures of chromicized catgut. After direct measurement of the inlet the abdominal wall was closed.

'The thoroughly mature male child was cared for by Dr. Farre't and cried lustily. The head was well ossified and nonconfigurable; a small caput was found over the left eye. The child $v$ eighed 3,400 grms. $(71 / 2 \mathrm{lbs}$.) and gave the following measurements: Length, $52 \mathrm{~cm}$.; bitem., $7.5 \mathrm{~cm}$; bipar., 9.75 $\mathrm{cm}$; occ-front, $12.5 \mathrm{~cm}$.; occ-mental, $13.75 \mathrm{~cm}$; subocc.-breg., $10.0 \mathrm{~cm}$; occ-front-circum., $37.0 \mathrm{~cm}$.; suboce. greg. circum., $33.0 \mathrm{~cm}$.

The involtion progressed rather slowly and at the time of the removal of the sutures the uterus was found to be adherent to the abdominal wall throughout the entire line of the wound, resulting in an involution which took place laterally, but hardly at all longitudinally-the uterus being long and narrow in form and extending to the umbilicus.

The convalesence was interrupted by a slight pleuritis, but at the end of the fourth week she left the hospital with her babe in excellent condition. Examination about three months later showed the condition practically unchanged.

\section{IDENTIFICATION.}

The measurements in this case are very interesting as - showing a pure type of the "funnel pelvis" (masculine 
or infantile pelvis), by which is meant a pelvis with normal or only slightly contracted inlet and high lateral walls which converge strongly downward to a markedly contracted outlet. In the identification of this pelvis it is necessary to exclude certain anomalous pelves wherein the contracted outlet exists only in association with characteristic deformity of the vertebral column, such as kyphosis and spondylolisthesis, as well as those cases of uniform generally contracted pelves wherein there occurs a slight increase of contraction toward the outlet.

The absence of vertebral deformity excludes the first two, and the measurements are so characteristic of the funnel type that the diagnosis can not be confused with the uniform generally contracted pelvis.

The patient is $158 \mathrm{~cm}$. high, with large, full and mature breasts, noticeably slight in figure with narrow hips and strongly converging genitocrural folds. The physiologic lumbar lordosis is diminished, no kyphosis, no rostration of symphysis, iliac venters rather straight and no evidence of early rachitis.

External measurements with tape and pelvimeter give sp., $19.0 \mathrm{~cm}$.; crests, $22.0 \mathrm{~cm}$.; troch., $26.0 \mathrm{~cm}$.; Baudelocque, $19.0 \mathrm{~cm}$.; circumference, $77.5 \mathrm{~cm}$.; left oblique, $19.5 \mathrm{~cm}$.; right oblique, $20.5 \mathrm{~cm}$.; post spines, $8.5 \mathrm{~cm}$. (average 7.5 ); and on same plane with sacrum. The sacrum is 16.0 long (average 10.3) and very narrow. Tip of coceyx to lig. arcuatum $7.0 \mathrm{~cm}$.; tip of sacrum to lig. arcuatum $9.7 \mathrm{~cm}$. outside, or allowing $1.0 \mathrm{~cm}$. for thickness of sacrum $8.7 \mathrm{~cm}$. inside (Klien's average 12.5, Garfuukel's average $12.3 \mathrm{~cm}$.). The distance from tuberosity to tuberosity measured by the Breisky or Chantrevil methods and the Ayers pelvimeter was 8.5 $\mathrm{cm}$, there being no practical difference in the result from either method.

The tip of the sacrum is easily accessible by the vagina and the coccyx projects acutely into outlet without ankylosis. The pubic arch is narrow, the symphysis high, the ischiatic spines also project markedly into the outlet. The linea innominata appear to be almost parallel, and the attempt to measure the conj. diag. never succeeded, as the promontory was apparently pushed upward and backward and was inaccessible to examining finger.

The inlet measurements were made directly before closing the abdomen and gave c.v. $11 \mathrm{~cm}$. and transverse of $13.0 \mathrm{~cm}$. Thus the inlet is as large as the average and the outlet is contracted in both diameters.

\section{CLASSIFICATION.}

Klien, who has made an exhaustive study of this pelvic deformity, classifies the varieties as follows:

1. Funnel pelvis with normal or only slightly diminished conjugate of strait in which-

A. Distance between the two tuberosities is only relatively short, but distance from tuberosities to sacrum is so small that both together make labor impossible.

B. Distance between the two tuberosities is absolutely so small that the head can not pass.

2. Funnel pelvis with conj. of pelvic strait absolutely too short for head to pass unreduced-

A. Without shortening of transverse diameter of outlet.

B. With contraction of transverse diameter of outlet.

'The very great importance of the pelvis strait is here well emphasized. Contraction in the sagittal diameter may be so great that the unreduced head can not possibly pass, even though the tuberosities are far aparton the contrary, the antero-posterior diameter of strait may be normal, or relatively so, but the contraction of the distance between the tuberosities is so great that this point assumes the position and importance of the pubic arch, the occiput stems against it and the head is forced so far back that labor is impossible.

In the study of 439 labors Klien makes the following deductions, which I quote in brief :

Where the pelvis is otherwise normal and the distance between the tuberosities is less than $9.5 \mathrm{~cm}$., a mature child will give trouble during labor whenever the presentation is pelvic or shoulder.

For unreduced heads in vertex position the boundary line for serious but not insuperable obstruction is found when the distance between tuberosities is $9.8 \mathrm{~cm}$., other pelvic measurements normal.

The conjugate of the pelvic strait is absolutely too small to permit the passage of the mature unreduced child when it is under $9.0 \mathrm{~cm}$.

Hence, in classifying our pelvis according to Klien's system we find that the conjugate of the strait being less than $9.0(8.7 \mathrm{~cm}$.) and the marked transverse contraction of the outlet being associated therewith, it should be placed in group $2 \mathrm{~B}$, which corresponds to the uniform generally contracted funnel pelvis of Schauta. According to Klien it is impossible for a mature unreduced head to pass this outlet.

\section{ETIOLOGY.}

Very little can be said concerning the etiology of this pelvic anomaly. Schauta believes it results from an original abnormal formation (abnormal height of small pelvis), whereby the promontory is placed high and pushed back, and under the influence of the body weight the shape is brought about in a manner similar to the kyphotic pelvis.

The altered direction of the burden explains the further changes in the reciprocal positions of the pelvic bones which unite for a common purpose.

While unable to add to this unsatisfactory explanation, I would like to emphasize the fact that the significant length of the sacrum and the abnormal height of the lateral pelvic walls must, in a normal convergence of the same, produce a definite contraction of the outlet as compared with the pelvis of normal height.

In support of the theory which minimizes the influence of the body weight, Fehling (confirmed by Thompson) shows that transverse expansion of the brim is present even at the third month of intrauterine life, and that the "long oval" form supposed to be normal in the fetus and newborn is a rare and pathologic-hence the name "infantile" as applied to the funnel pelvis is a misnomer. He concludes: (1) that the transverse expansion depends on the original formation and appears early, hence its production by the body weight is superfluous; (2) that sexual differences are generally present from the fourth month intrauterine, and are perfectly distinct at birth. These facts support the theory that the funnel pelvis is a primary developmental anomaly, and also if so much importance could be attributed to the unusual distribution of the body weight, a kyphosis might result therefrom, and the evident relationship between the kyphotic and the funnel pelvis could be explained, certainly in some instances, along the lines suggested by W. A. Freund in his paper on the pelekogenous origin of vertebral deformity.

\section{FREQUENCY}

It is almost impossible to secure a definite jdea of the frequency of this deformity. In Breisky's clinic at Prague, where more than usual attention is given to the contraction of the outlet, there were found 122 funnel pelves of all kinds among $2,0 \% 0$ contracted pelves, or 
5.9 per cent. of the total collection as quoted by Schauta. Klien quotes Munch $1 \% .8$ per cent. of contracted pelves, Frankenhauser 13 per cent.

Both Schauta and Klien agree that these statistics are in no sense reliable, since no routine measurement of pelvic outlet is undertaken, and when performed a great variety of opinion exists as to what constitutes "funnel pelvis," and what degree of contraction shall determine. Prickards quotes 3,000 labors at Würtzburg, with 252 contracted, but no "funnel pelvis". is mentioned. Ludwig Savor among 50,621 labors reports four cases. Williams (Johns Hopkins) 1,000 labors with no funnel pelris. Dobbin (Johns Hopkins) one of masculine type in 350 pelves. Fleischmann 2,700 labors with 24 cases of funnel pelvis, which subsequent writers agree must be of slight degree. Schroeder says: "This is a very rare form of pelvic deformity, and even more rare is contraction to a serious degree." Ahlfield gives 8 cases of all kinds in 3,000 labors at Marburg. Olshausen in discussion says: "Very rare, one always thinks of kyphosis."

Klien states that pelves which conform to No. 2 B of his classification, namely, with an absolutely contracted sagittal diam. associated with contraction of transverse diam. of outlet, are extremely rare, and he gives only four cases which have been reported up to 1896-one being his own, and the writer has been unable to find another, diagnosed and reported in literature up to the date of the present case, which produced an insuperable obstacle to labor by the natural passage.

\section{CLINICAL COURSE.}

It can not be supposed that these deformities occur without producing a pronounced effect on the clinical course of pregnancy and labor. Where the inlet is not markedly contracted the pregnancy will not differ from other cases, and where definite contraction exists the babe will be carried high, but the principal difficulty will occur when labor begins, for contraction of pelvic outlet is more serious than contraction of the same degree at inlet.

In mild degrees of contraction where spontaneous labor is possible the second stage will be prolonged and serious lacerations are probable. Difficulties in rotation will be noticed because the form of the pelvic outlet prevents normal rotation. Pain weakness from the low position of the child in the lower uterine segment with its scanty musculature is also probable, especially in primaparæ. It is in cases of serious contraction of the outlet, however, that most difficulties arise.

As the case is not usually diagnosed until the first labor is well on nearly every variety of obstetric emergency and operation is met. The conditions are worst when the child is mature with an after-coming head.

In Ahlfield's 8 cases are found, 2 forceps operations, 1 perforation, 1 spontaneous premature labor, 2 artificial induction of premature labor, 2 labor stool. Greuser, craniotomy at outlet. Brummerstadt 2 cases, one stillborn, one saved with difficulty and mother died 36 hours later. Landau, 2 cases craniotomy. Jewett 1 case symphysiotomy. Newman 1 case symphysiotomy, mother died, child lived. Winterberg 1 case symphysiotomy, both lived. Klien reports:

CASE 1.-Tub., $7.6 \mathrm{~cm}$; ant. post., $12 \mathrm{~cm}$.; forceps after long tedious labor. Second stage, nine and one-half hours, laceration cervix, pressure necrosis in vagina; recovery. The head was easily configurable in this case.

CASE 2.-Tub., $8 \mathrm{~cm}$; ant. post., $12.25 \mathrm{~cm}$.; head four hours visible at outlet; forceps; good result.
CASE 3.-Tub., $7.6 \mathrm{~cm}$; ant. post., $12 \mathrm{~cm}$; version and ext.; good results.

These cases, quoted in brief, serve to show the difficulties associated with labor in this variety of contracted pelvis. In all of Klien's cases the contraction was transverse only, antero-posterior diameter normal, which accounts for his results. Where the head is small and easily configurable, and this I regard as most important, the results are moderately satisfactory, especially if the space between the tuberosities and the sacrum is large enough to permit the passage of the head, but a very slight anomaly, such as a small protrusion of the ischiatic spines will disturb the entire mechanism and possibly cause death of mother or child, or both.

Another feature of this pelvis which has an important bearing on the severity of the labor, is the height of the lateral walls and the length and straitness of the sacrum.

Undoubtedly. the long converging walls which are characteristic of the true "funnel pelvis" are the frequent cause of errors in rotation and position, which seriously complicate a condition already sufficiently grave.

\section{PROGNOSIS.}

Prognosis in general is not favorable in these cases, but the result depends on the degree and variety of contraction, and especially on the operation, which latter in turn depends on an accurate appreciation of the size and shape of the pelvis.

If left to Nature the soft parts experience deep crushing injuries, which in some cases expose the pubic rami besides producing fistulæ from the long compression. The extreme distention of the lower uterine segment may lead to uterine rupture. For the child the danger of asphyxia is greater than in other deformities, owing to the earlier escape from the uterine body. We find also the characteristic pressure marks appear on skull of babe and even fractures occur. The prognosis is most favorable where the fetal head is small and easily configurable and the outlet is contracted in one diameter only. POSSIBLE OPERATIONS.

The measurements of the child's head in the present case demonstrate conclusively that its passage unreduced through the pelvis was impossible, and even if the head had been easily configurable, instead of hard and well ossified, I believe the birth of a living child could not be expected. These conditions could only result in a long, hard labor, with operative termination and doubtless a dead child.

In view of the strong desire of the parents for a living child the various operative procedures were carefully considered. The induction of premature labor naturally came first in point of time, and with the modern aids to the preservation of the child after birth, presented many hopeful features, but aside from the uncertainty of the date of conception there was continually in mind the imperfections and uncertainties of our means of determining the size of the fetal head, either by instrumental or external palpation and the necessity was urgent to determine not alone the size, but especially the form and consistency of the head, and as this could only be approximate at best, the success of the operation becomes highly problematical, even in cases where the time of conception is approximately known.

Besides this, the fetal mortality for many reasons is large, and shows, according to Krönig, a variation from 55 per cent. in the pelves showing the most contraction to 25 per cent. in pelves with c.v. between 9.5 to 10.5 
$\mathrm{cm}$. Consideration must be given also to the fact that premature children show a large mortality during the first year of life (from 19.5 per cent. to 28 per cent., as given by different authors), which directly or indirectly may be attributed to the prematurity, and the maternal mortality in these cases is from 1 to 2.2 per cent. ${ }^{1}$

Hence the chances seemed slight that a living child could be promised by this method, and it was rejected. The choice then rested between symphysiotomy and conservative cesarean section at term. The statistics give approximately the same mortality for each ( 2 to 10 per cent.), and a fetal mortality ranging from 15 to 25 per cent. in symphysiotomy as compared with 2.5 per cent to 5 per cent. in cesarean section, and in accordance with these conditions the cesarean operation was decided on as giving a maximum chance for a living child and a maximum of safety for the mother.

\section{FUTURE PREGNANCIES.}

The termination of this pregnancy has been in every sense satisfactory, but as the patient is only 21 years old and has the greater part of her sexual life before her, we must consider her future pregnancies. The moral question of sterilizing a woman by removal of the tubes or a portion thereof after the cesarean operation is still unsettled, but there seems to be no justification for depriving the woman of her ability to conceive and bear children when the mortality by the various operative procedures is so low. Both the cesarean operation and ventrofixation seem to lessen the chances of subsequent conception. But we can not rely on sterility, and it is probable that pregnancy will again occur. The adhesion of the uterus to the abdominal wall amounts to a ventrofixation and must be considered in reference to subsequent pregnancies. Abel reports several cases of abdominal adhesions after cesarean section where the operation was done two or three times on the same patient.

If the adhesions remain broad and firm $(1 / 3$ of the cases) the course of the pregnancy will be materially interfered with and expansion can occur only in breadth - the uterus can not rise toward the sternum-the axis will not correspond with the pelvic axis and malpresentations will occur, and abortion takes place in about 8 per cent. of the cases.

If pregnancy goes to term the risk of sepsis in subsequent operations will be diminished where the adhesions permit opening into the uterus in situ without entering the peritoneal cavity (Spencer). Usually these adhesions produce some stretching and tearing pains during subsequent menstruation, but inside of a year, or during the first half of the next pregnancy they disappear or remain only as long loose strings which cause no difficulty.

A review of the patient's first pregnancy and labor, in the light of our present knowledge, shows that the version and extraction was unwise; indeed, when the head is non-configurable version must not be attempted, for Klien's report demonstrates the aftercoming, nonconfigurable head is impossible of delivery in such a pelvis. Head-first labors give a possibility of delivery when the child is premature and head soft, and under such conditions version is permissible.

Either craniotomy or cesarean section should have been done, with a preference for the first, since she had been repeatedly examined, but there seems to be no valid reason against terminating all subsequent pregnancies in this patient by cesarean section.

1. Heyman: Arch. f. Gyn., Bd. lix, Heft. 2, 1899.
BLBLIOGRAPHY.

Abel : Arch, of Gyn., 1900

Ahlfield: Lehrb o Geb.

Bauer: Ztsch. f. Geb. u. Gyn 1898.

Champneys: Tr. Lond. Obs, Soc., vol. xxy.

Dobbin: Am Jour. Obst, vol. xxxvi.

Dickinson : Am. Jour. Obst. 1901 .

Fleischmann : Ztsch. f, Heilk., 1888

Freund W. A.: Gynakol Klinil.

Fehling : Arch. f. Gyn., 1876 .

Heyman: Arch. t. Gyn., 1899, Bd. lix, Heft. 2.

Klien: Volkman's Samuel Klin. Vortrag, 1896.

Krönig: Therap. beim, Enger Becken.

Prickards : Inaug. Diss., Mainz, 189

Reynolds: Tr. Am. Gyn. Soc., 1890.

Schroeder : Lehrb. d. Geb.

Schauta: Muller Handbuch.

Veit: Ztschr. f Geb u. Gyn., Bd. ix, 1883

Williams : Obstetries, vol. i.

\section{THEORIES OF THE TRANSMISSION OF HEREDITARY SYPHILIS.*}

ALFRED SCHALEK, M.D.

Instructor of Dermatology and Genito-Urinary Diseases, Rush Medical College. CHrCago.

The fact of the heredity of syphilis was known to Paracelsus, who, in the year 1560, asserted that this disease was due to some unknown virus circulating in the blood, which also infests the semen and during conception is transmitted with it to the fetus.

Still, at the present time, we are not able to recognize positive laws as to the methods and conditions of the transmission of hereditary syphilis, and must fall back on theories based entirely on empirical conclusions. Until the specific micro-organism of syphilis is demonstrated scientifically and beyond doubt, these theories will never be more than probabilities-the more so as we find ourselves heavily handicapped in the attempt to make use of our clinical material. The protean nature of syphilis, where we might say that exceptions form the rule, the necessity to observe cases over periods of many years and finally our dependence on the history of at least three persons involved-an evidence which is none too free from objections as to its trustworthiness-all these factors make it difficult to arrive at satisfactory results.

We do know that syphilis is transmitted from the parents to the fetus. The questions which arise next are the following: 1 . Which of the parents may be responsible for the transmission of the disease? 2. What are the ways and means by which the virus is transmitted? 3. What are the circumstances most favorable for the hereditary propagation of the disease?

The possibilities of a communication of the virus to the fetus are threefold: the generative organisms, the sperm cell or the ovum, or both, may contain the contagions substance a priori; the fetus may become infected through the maternal blood circulation; and finally, all these factors may act in combination. To determine how much is real in these different influences, to which the transmission of syphilis is attributed, we must take the problem to pieces and examine one after the other separately.

\section{INFLUENGE OF THE FATHER.}

The point whether syphilis can be conveyed to the child by the father alone, without infection of the mother, is a subject of much controversy. We shall now try to establish such a possibility on the basis of logical conclusions. To prove this supposition we must in the first place be able to exclude any participation of the mother, and for this reason be absolutely certain of her health. The mere absence of specific manifestations

* Read by invitation before the Rock Island County Medical Society. 